\title{
FRAGMENTOS RESILIENTES DA PAISAGEM: PRAÇA E PRACIALIDADE NO MUNICÍPIO DE DUQUE DE CAXIAS NO RIO DE JANEIRO
}

\author{
Ingrid Souza ${ }^{1}$ \\ Paloma Ferreira ${ }^{2}$ \\ Gustavo |zabel ${ }^{3}$ \\ Rafaelle Barbosa ${ }^{4}$ \\ Glaucineide Coelho ${ }^{5}$
}

Resumo: O artigo discuti a não existência de um sistema de espaços livres públicos no município de Duque de Caxias, na Baixada Fluminense do Rio de Janeiro. Para isso, destacamos as praças caxienses em suas funções cívicas e de lazer, como elemento formal de composição de tal sistema. Entendemos que a não conformação de um sistema de espaços livres públicos, indica uma infraestrura da paisagem fragmentada, que subverte o sentido do espaço público como lugar de encontro da vida, no que tange as possibilidades de apropriação espacial, fazendo emergir intencionalidades que recriam formas e usos para os espaços, o que torna visível a resiliência num sentido que a população transforma de maneira oportuna os espaços da cidade em praça. Nesse contexto teórico, nosso objeto de estudo, os bairros do Centro e 25 de agosto em Duque de Caxias, se colocam territórios propícios a constituição de parcialidades resilientes, o que nos convida a uma nova maneira de olhar a cidade.

Palavras-chave: SEL; Resiliência; Praça; Pracialidade.

\footnotetext{
${ }^{1}$ Arquitetura e Urbanismo/UNIGRANRIO, Brasil. E-mail: palomaferreira@unigranrio.br.

2 Arquitetura e Urbanismo/UNIGRANRIO, Brasil. E-mail: ingridsds.aqr@unigranrio.br.

3 Arquitetura e Urbanismo/UNIGRANRIO, Brasil. E-mail: gustavo.izabel@unigranrio.com.br.

${ }^{4}$ Arquitetura e Urbanismo/UNIGRANRIO, Brasil. E-mail: rafaelle.barbosa@unigranrio.br.

${ }^{5}$ Arquitetura e Urbanismo/UNIGRANRIO, Brasil. E-mail: coelhoglauci@unigranrio.edu.br.
} 